\title{
Agile Portfolio Management at Finnish Broadcasting Company Yle
}

\author{
Maarit Laanti \\ Nitor Delta \\ Kalevankatu 3 A 45 \\ 00100 Helsinki, Finland \\ Maarit.Laanti@nitor.fi
}

\author{
Rami Sirkiä \\ Nitor Delta \\ Kalevankatu 3 A 45 \\ 00100 Helsinki, Finland \\ Rami.Sirkia@nitor.fi
}

\author{
Mirette Kangas \\ Yle \\ Radiokatu 5 \\ 00024 Helsinki, Finland \\ Mirette.Kangas@yle.fi
}

\begin{abstract}
Agile methods provided a revolution in how projects are managed and executed. Companies strive to adopt agile methods on all levels of their organizations. Yet Agile Portfolio Management is a new topic in research, and only few experience reports exist so far on how companies have taken Agile Portfolio Management into use. This paper fills the gap by describing how Finnish Broadcasting Company Yle adopted Agile Portfolio Management and what the benefits of this new approach are.
\end{abstract}

\section{Categories and Subject Descriptors}

K.6.3 [Management of Computing and Information Systems]: Software Management - software process.

\section{General Terms}

Management.

\section{Keywords}

Large-scale agile software development, agile methods, software engineering, project management, portfolio management, Scaled Agile, beyond budgeting, lean finance, agile finance, agile budgeting, lean budgeting, lean agile finance, agile planning.

\section{INTRODUCTION}

Three megatrends shape the world around us, namely the wider and wider use of software inside products, digitalization, and the globalization of products and services. The digital revolution continues to destroy firms that aren't anticipating this change [1]. Agile project management methods caused a silent revolution in the way projects are organized and executed $[2,3]$.

Permission to make digital or hard copies of part or all of this work for personal or classroom use is granted without fee provided that copies are not made or distributed for profit or commercial advantage and that copies bear this notice and the full citation on the first page. Copyrights for third-party components of this work must be honored. For all other uses, contact the Owner/Author.

Copyright is held by the owner/author(s).

XP 2015 Workshops, May 25-29, 2015, Helsinki, Finland

ACM 978-1-4503-3409-9/15/05.

http://dx.doi.org/10.1145/2764979.2764980
Unlike traditional portfolio management that tries to plan accurately years ahead, agile portfolio management applies rolling planning, rolling budgeting and forecasting, options thinking and capacity and feedback-based balancing. Yet there exists only little research on this subject. This paper describes one case study explaining how Agile Portfolio Management was taken into use in Finnish Broadcasting Company, and what the benefits were.

Finnish Broadcasting Company Yle operates four national television channels that are also available as simulcast HDchannels, and six radio channels and services complemented by 25 regional radio programmes. In 2013 Yle TV1 was the most popular television channel in Finland. Yle's share of daily television viewing was $41,9 \%$. Yle's radio listening was $51 \%$. Yle programmes and content reach $100 \%$ of Finnish people yearly.

People generally consider Yle to be a reliable source of news and current affairs. The company plays a major role in producing and presenting programmes dealing with national arts, educational programmes and children's programmes. Yle's services to the public also cover special and minority groups. Yle's operations are financed by public broadcasting tax. [4]

Yle has set its strategic target to be producing value to society, to serve all Finns and to have the media sector's best competence [5]. The best competence is implemented by having the best people and partners, to boldly renew the company operations and to operate in transparent, effective way.

Agile Portfolio Management is perceived to be one of the ways to improve efficiency of operations and transparency. Agile way of working is also a radical improvement to how the management used to be run. Nitor Delta was selected to offer agile consultation and services to Yle after a competitive public tendering in November 2013.

Improving productivity and quality is a key concern of any organization, but there are also some global trends that amplify the reasons why organizations are looking into ways to boost their performance.

1. Change or die. New innovations and new technologies come to markets with increased speed. $[6,7]$

2. Constant need for further innovations. What is there is quickly copied - a need for constant innovation to enable competitiveness. [8,9]

3. Transaction cost is small or almost absent compared to traditional settings. Publishing new (software) versions in the 
cloud is "free" once the cloud and the continuous deployment infrastructure is there. This leads to a faster ROI circulation. $[10,11]$

4. Markets are more unpredictable than before. There is a need to be flexible with investments and capacity. $[12,13]$

All these questions how to create and nurture more innovations and how to compete in unpredictable markets are addressed by the Agile Portfolio Management. In the $8^{\text {th }}$ Annual State of the Agile survey in 2013 only $16 \%$ of the companies reported to run Agile Portfolio Management [14]. This paper examines how Agile Portfolio Management was deployed and what the benefits of Agile Portfolio Management deliver in practice using Action Research.

\subsection{Agile Organization}

An Adaptive (or agile) Organization can be seen to consist of three layers, as described in Figure 1.

On the Team level of an Agile Organization there are development teams that follow Scrum, Kanban or Scrumban. That level boosts productivity in the scope of the teams - research reports vary between 17 to $712 \%$ of performance improvement after adopting Scrum, the average being $67 \%$ [15]. Naturally, the amount of productivity gained depends a lot not just from the end state but also from the initial state. A bit more reliable performance improvement metric would be the waiting time for an internal integrated and tested release made (the latency time waiting for the integration to be completed) versus the latency time after continuous integration or continuous deployment has taken into use. It is not unusual to gain up to 200 percent faster cycle times, although as high improvement as 10000 percent can be reached-depending on how slow your initial system is [16].

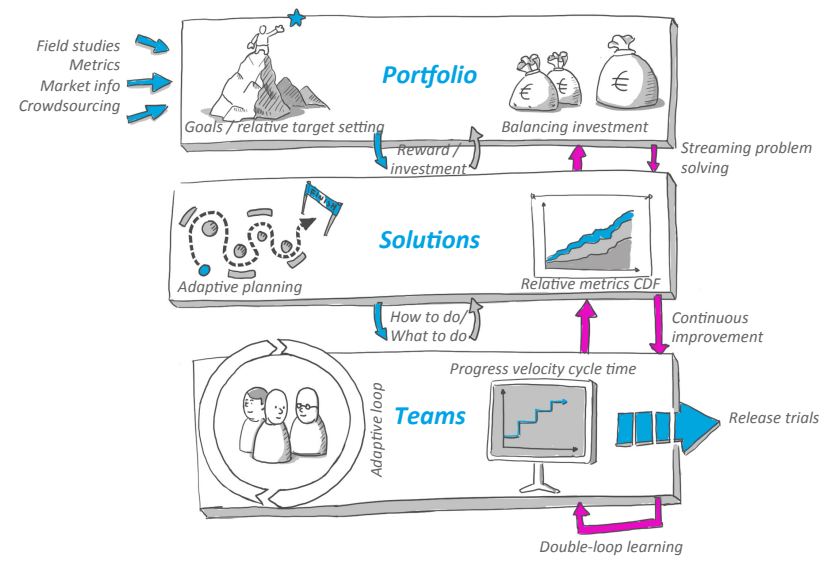

Figure 1. Model for Adaptive Organization [17]

The Solution level arranges your work for maximum throughput. The concept of project is abandoned in agile, because ramping a project up and down is time-consuming. Thus the word Solution is taken into use in this level, instead of Program or Project. A continuous flow is a more economical way of organizing work. That is why organizing work on this level is based on Features. Features may have very different value to the user, so you may want to focus on developing the highest value Features first. A study at Maersk [18] shows that the value of different Features may vary a lot, and packaging different value features to the same project leads to spending a lot of time in less-value producing tasks.

Typically organizations that organize their work as projects also have many parallel projects ongoing. Swapping between different projects can be time consuming, and all the parallel projects are delayed because the more projects you have going in parallel, the less time is allocated to each project per week. It is better to have focus in development, and sequence the Features one after each other. That means all the development time is allocated to fewer Features, and the cycle time shortens. Those Features that touch the same areas of the code or must be done by the same teams can be done sequentially, one after each other. Everything that is not interdependent and can be done in parallel should be executed in parallel for maximum throughput. Typically there is no limit to how much testing can happen in parallel.

The two levels are sufficient, if you have only single product or service that comprises of small Features only. If you have multiple products or services to manage or your product or service consists of new items that need several Features to perform a meaningful function you need the third layer, a.k.a. the Portfolio level. On portfolio level the decisions on how much is invested in each of the products during the next period of time are made based on past performance. Larger new development activities are defined as Epics. An Epic is a development item, a rougher idea, a feature set or a new Product concept that is of similar nature as a User Story. Epics are gradually refined as Features, which are refined as Stories and Tasks, see Figure 2.

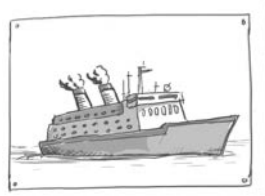

Epics

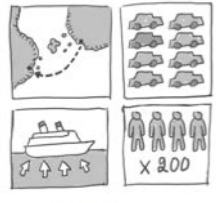

Features

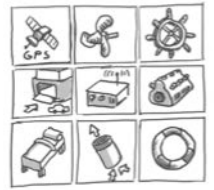

Stories

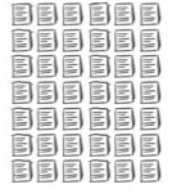

Tasks
Figure 2. Epics, Features, Stories and Tasks illustrated

\section{AGILE PORTFOLIO MANAGEMENT PRACTICES AND RATIONALE}

This chapter lists the Agile Portfolio Management Practices along the communicated rationale of each practise in Table 1. These practices are based on the Scaled Agile Framework definition of Agile Portfolio Management [19].

Table 1. Practices of Agile Portfolio Management and the Rationale of Each Practice

\begin{tabular}{|c|c|c|}
\hline 1 & Practice & Rationale \\
\hline $\begin{array}{c}\text { Epics, } \\
\text { prioritization } \\
\text { of Epics }\end{array}$ & $\begin{array}{c}\text { Avoid a long queue of development } \\
\text { items that will get outdated. Specify the } \\
\text { new Epics just in time when needed. } \\
\text { Focus on value derived from each Epic. }\end{array}$ \\
\hline 2 & $\begin{array}{c}\text { Portfolio } \\
\text { Backlog } \\
\text { consisting of } \\
\text { Epics) }\end{array}$ & $\begin{array}{c}\text { implementation needs. The fractal } \\
\text { backlog structure helps development } \\
\text { teams to identify in general what is the } \\
\text { larger entity (i.e. Epic) that the Stories } \\
\text { under development will contribute to. A } \\
\text { change of priorities in Portfolio }\end{array}$ \\
\hline
\end{tabular}




\begin{tabular}{|c|c|c|}
\hline & & $\begin{array}{l}\text { Backlog enables the company to } \\
\text { quickly change its strategic direction. }\end{array}$ \\
\hline 3 & Epic Owner(s) & $\begin{array}{l}\text { Each Epic has an Epic Owner that is } \\
\text { responsible for making all the decisions } \\
\text { regarding the contents of that Epic. An } \\
\text { Epic owner remains the same from idea } \\
\text { until the Epic is ready, and participates } \\
\text { all negotiations and meetings } \\
\text { considering the Epic, thus resulting to } \\
\text { lots of tacit information. }\end{array}$ \\
\hline 4 & $\begin{array}{l}\text { Enterprise } \\
\text { Architect(s) }\end{array}$ & $\begin{array}{l}\text { Architecture is a business decision. } \\
\text { What architecture solutions are used } \\
\text { impacts the Return On Investment, i.e. } \\
\text { the payback of each investment } \\
\text { decision made. Thus Enterprise } \\
\text { Architects analyse and make decisions } \\
\text { regarding the possible future } \\
\text { architecture solutions, e.g. what cloud } \\
\text { solution, database or framework a } \\
\text { company should use. }\end{array}$ \\
\hline 5 & $\begin{array}{c}\text { Program } \\
\text { Portfolio } \\
\text { Management }\end{array}$ & $\begin{array}{l}\text { Program Portfolio Management is a } \\
\text { group of senior managers, strategy } \\
\text { planners and directors that make } \\
\text { portfolio decisions and prioritize the } \\
\text { Portfolio Backlog jointly. This usually } \\
\text { leads to better decisions as all opinions } \\
\text { are heard and viewpoints considered. }\end{array}$ \\
\hline 6 & $\begin{array}{l}\text { Strategic } \\
\text { Themes }\end{array}$ & $\begin{array}{l}\text { Strategic Themes express the intent to } \\
\text { which direction the enterprise would } \\
\text { like to develop its portfolio, i.e. what } \\
\text { kind of new strategies it will implement } \\
\text { in the future. Epics are derived fro } \\
\text { Strategic Themes. The practise of tying } \\
\text { Epics, Features and Stories ensures that } \\
\text { all work is checked against strategy, } \\
\text { and provides feedback also to strategy } \\
\text { process. }\end{array}$ \\
\hline 7 & $\begin{array}{l}\text { Portfolio } \\
\text { metrics }\end{array}$ & $\begin{array}{l}\text { Portfolio metrics measure the } \\
\text { enterprise's performance at the highest } \\
\text { level. They can include measures like } \\
\text { employee engagement and market share } \\
\text { / development. }\end{array}$ \\
\hline
\end{tabular}

\subsection{Previous Research on Agile Portfolio Management}

As Agile Portfolio Management is such a new practise, there exists only few research reports on this subject.

Tengshe and Noble implemented an agile Program Management Office (PMO) and portfolio at Capital One auto finance [20]. They had multiple projects on-going in their portfolio at the same time, with competing resourcing. They created multiple prioritized portfolio backlogs. They also created a scheduled release process in order to get rid of resource overlaps. After $40+$ completed agile projects they were able to elevate customer satisfaction up to $100 \%$. They also measured that the project completion times were reduced $50 \%$.

Thomas and Baker have implemented agile portfolio management in DTE Energy [21]. They report that legacy mindset and processes such as widget engineering, seeing IT as an order-taking organization, annual budgeting cycle, IT investment change management and delivering in big batches impede agile mindset. Instead of annual budgeting they implemented a new process where value is being discussed, not just the cost. Instead of IT change management they put their projects into prioritized backlog, and funded only three months at a time. They also matched the amount of work started to the available capacity. Reducing amount of new work started to available capacity forced them to have overall prioritization inside the whole organization, not just inside one single business unit. Instead of the order taking they held series of workshops where the mindset was changed to look how to ensure success. They also established one-age Project Charter tool for project approvals instead of the former longer project plans.

Rautiainen, Schanz and Vähäniitty [22] explain how they changed from 214 resource competing projects in Paf (Ålands Penningsförening) into the use of one joined, prioritized backlog, simple project proposals and a supporting tool. They have also reduced the number of projects in the backlogs into 30 . The driving force is to reduce the number of ongoing projects at a time so that the cycle times get much faster. They have also reduced the portfolio into a much simpler, and got rid of the pet projects that were started in the past using vague arguments ("I just want this").

Stettina and Hörst [23] used semi-structured interviews to compare companies doing traditional Portfolio Management with companies doing Agile Portfolio Management. They reported that agile portfolio management is leading to:

1. Transparency of resources and work items, improving trust, decision making, and resource allocation.

2. Collaboration, close collaboration based on routinized interaction and artifacts enabling frequent feedback loops across domains.

3. Commitment to strategically managed portfolios.

4. Team orientation, removing unrest in resource allocation and building capabilities in teams.

\section{DEPLOYMENT OF THE AGILE PORTFOLIO MANAGEMENT STRUCTURES}

Agile Portfolio Management was taken into use during 2014 in Yle in the area of Internet development. First, a current state analysis was carried out. Then, the new possible future state was defined and illustrated as the ideal future state.

The developing vision provided a mechanism and a communication tool that described the intended way of working, its key principles and enabled discussion of the organization's existing structures and disciplines and how these two can match each other. No two agile portfolio implementations are the same, and the difference comes from the purpose of the organization and the clients it serves.

While the vision was discussed, people also participated in 2-day trainings in order to learn the principles and practices of Scaled Agile. We also held a series of workshops where we simulated the new model and tried to see how it fits to Yle. Our first attempt was to teach the new approach to people so that they would set the practice up themselves. However, this approach led only to partial success. In the end we had to give up and try an alternative way: 
to simply set up the Kanban board ourselves. This would have not been possible without strong support from the upper management.

Part of the adoption was to set up new governance structure in place. Now the Epics are monitored by a Roadmap Group, which is responsible for making decisions on Epic priorities.

In the end Agile Portfolio Management was taken into use in just nine hectic weeks. The tasks completed included setting up the Kanban board on the wall, specification of the first Epics, identifying the key persons from each focus area to contribute to the work and to communicate the contents. The core team setting it up was proud but exhausted when demonstrating the wall and communicating the first roadmap to the executives.

\subsection{Enabling Agility with Rolling Fund Allocation Model}

Established organizations often have management level processes that are entwined. A strategy process which verbalizes the overall direction and goals; a resource allocation process owned by the $\mathrm{CFO}$ which dedicates resources to goals; and HR processes which tie performance of the unit, team and individual to incentives. These processes also penetrate to lower levels of the organization. Each unit/division translates the strategy into actions and initiatives, funds are being further distributed to teams and projects and scorecards and incentive plans are fixed.

One of the key enablers for portfolio level agility with Yle was to leave part of the annual budget unallocated. We defined a rolling allocation model where all $(100 \%)$ of the first quarter available funding was allocated, on the second quarter out give only $80 \%$ and leave $20 \%$ to be allocated based first quarter increments, demos and user feedback. Third quarter out, allocation was only $60 \%$ of the expected budget and fourth out with $40 \%$. This limited pre-allocation ensured that management still had funds to allocate in agile manner, to areas where they later during the year would see the biggest need.

We expect that this model promotes faster increments, faster protos and demos to attract part of the remaining funds; it reduces the importance of annual planning and promotes continuous planning. As there is a substantial part of the funds already allocated for the next 12 months ( $40 \%$ for fourth quarter), the model gives room for long leadtime items, some security and a sense of longevity. Also the earlier practice to start projects in January in order to secure funding - which in turn reduces agility - might be history.

While management accepted this rolling allocation model without hesitation, some concerns were verbalized: as the secured funding per each of the domain (initiative, project, unit) is smaller, more clarity on strategy is needed and more pruning is needed at the beginning of the year. We might have not seen all the implications - after all this is a relatively major change compared to the old model where funds were given based on applications, applications that should well define the goals and the expected outcome. Now the new rolling model relies on management vision for where to put resources - even when not knowing all the details.

\subsection{Simplifying Purchase Order Approvals}

Upon implementing the Global Backlog, Epic Value Statements and Roadmap, we recognized that we could actually simplify the procurement orders downstream a lot. We used Backlog and
Roadmap approval as the first approval stage and the second approval was part of the actual purchase order to a specific vendor. This fulfilled the double acceptance criteria for the development spending.

\subsection{Capex vs. Opex}

In some organizations the cost center structure becomes an inhibitor of agile development [24] but this was not the case in Yle. Hence it was a surprise to find that annual budget for the studied part of the development had separate budget for capital expenditure and operative expenses. While it is understandable for the finance function to improve Profit and Loss (P\&L) planning accuracy, it posed a minor restriction to the development unit and resulted in that funding for Opex was seeked elsewhere. The solution to this was that the business controller did a rolling forecast for Capex, gave more freedom to development units and took a slight hit on planning accuracy.

\section{OBSERVATIONS ON BENEFITS OF THE NEW APPROACH}

The primary goal of Agile Portfolio Management was to set up a steering mechanism that is compatible with the agile way of working that the development teams use. However, the implementation of Agile Portfolio Management in Yle has revealed also some additional benefits. The list of benefits is based on our Action Research [25] observations and feedback from people using the new process. Only those benefits have been listed that have been verified from more than one source.

A portfolio wall (Kanban wall and Roadmap) with visibility to all on-going Epics from idea to implementation has brought new kinds of visibility and transparency into on-going activities. The transparency is implemented with a Portfolio Kanban wall. When the wall was set up the first time, there was double amount of good ideas for implementation than what there was budget for. This is typical for all new portfolio visualizations, because traditionally there is little support in matching the work with the organization's existing capacity. Now, with the new visibility it was clear that not all ideas could be executed and prioritization could start before the work is started - work that would later be killed and classified as waste.

Budget constraints with common visibility on all on-going activities stimulated discussions if some of the Epics could be done with a joined effort, rather than separately funded efforts. These discussions have led to use of some shared code and elimination of some unneeded effort. The Enterprise Architects have been in a key role in these activities.

The visualization on the Portfolio level is also challenging management to set the expectations on a more realistic level. Adding a new Epic to the Portfolio Kanban is now less than 5 minutes of work. After the Epic is added, its business value is compared to all other Epics. If the Epic is considered valuable, it is specified in more detail. This is a significant improvement compared to the past, since previously all projects were specified in detail without knowing if the effort was going to be wasted if the project later was delayed and/or rejected. Now the uncertainty whether the Epic gets implemented is a valuable part of the process - it is natural that all ideas get to the table (or wall in this case) and through continuous prioritization, only the most 
valuable Epics get through. It is a single process for innovation (idea funnel), strategic focus (prioritization) and resource allocation (Backlog).

The new visibility and transparency have forced the managers to discuss and make joined decisions, instead of operating and making decisions only regarding their own areas. There is also improved awareness across the organization of what new services are under development. Previously each manager had only visibility to those projects they were steering themselves but none to other projects.

Specifying and approving Epics is also a lot faster than earlier. The budget is granted for each of the swim lanes on the Portfolio Kanban board, not for individual Epics or projects. In the past the approval of a new development idea could take a third of the development time of the whole project. Each project was approved in five stages. Now the approval process is continuous but conditional.

Funds are allocated to each swim lane and whatever is prioritized to top gets done. However if no progress is made, e.g. if the idea may be technically too challenging to implement, the idea might get cancelled. This is done in order to avoid pouring money to already doomed efforts. The work time is freed up to make progress on the actual content, while there is less time needed to work with old approval tools and systems.

It is very important to maintain the adaptability on all decisionmaking levels. New Epics may be raised, cancelled or progressed at any given time. This allows the company to focus on what is perceived as the most important activity at any given time.

In the past when the project got funded, it was given a budget. The budget was the same regardless of the project being a success or not. Now the budget is flexible. If a Focus Area (a swim lane) is able to demonstrate success it will be allocated more funds. This enables option thinking: investment on those initiatives that more prominently demonstrate success.

The main Strategic Themes guiding Epics in the Portfolio Kanban are presented for the next 12 months, and updated every 3 months. This kind of two-level rolling roadmap enables visibility to the coming development efforts. This provides a new kind of continuum as in the past the annual roadmap had very limited visibility during the last months of each year.

Now that we have also implemented tool support on Portfolio level, the whole organization has better understanding where the work they are doing is contributing to. Portfolio Kanban, Epics and Roadmaps along with progress reports are available regardless of the place and time in real-time dashboards.

\subsection{Selected Financial and Performance- related Benefits}

The process how the initiatives (earlier projects, now Epics) get resourced is now an integral part of the Portfolio Kanban - not a separate process where you first define the content and then apply for the funding.

The new Portfolio Management approach based on Epics and continuous mode rather than projects has changed the success criteria from 'achieving the project goals' into working software and - in the future - to user satisfaction.

All in all, whole funding, resource approvals and purchase order processes are less bureaucratic - the process itself is faster and allows to focus on content.

\subsection{Future Aspirations}

The new Portfolio Management has been seen so promising that there are aspirations for wider adoption of the new practice. This would require scaling and tailoring the practise created for Internet area outside software development, into Broadcast Programme and Media Planning. The motives and starting points are to the large extent the same with when this work was started in Internet area, but it is also important to have joint leadership and culture in all areas. Resourcing and prioritization of work should happen similarly in all divisions as there is also a need to prioritize the work jointly across the divisions, i.e. not just inside the Internet portfolio but also in between Internet area and the Programme and Media areas. This is especially important when developing transmedia content that is published simultaneously via multiple channels.

Media companies such as Yle are just recently starting discussions on transferring people from traditional media to Internet area. Adopting new leading methods is natural at this moment, because the future will be more and more Internet-based. It is vital for the future successes to prepare with adoption of the new Internet development methods and practices throughout the whole company.

In Internet area it is not enough to just make the offering (service) available. One must also measure the usability and quality of the service, and the user retention rate. Users may also move from one medium to another very rapidly. Thus each Epic is paired with a Strategic Theme defining the target audience and estimated increase in business metrics (quality or quantity). After the Epic is implemented, the impact gets measured. That enables an organization to learn from the offering it provides, and the development efforts made. Traditional control mechanisms provide no means to measure the impact, so no learning happens and the user base cannot be systematically nurtured.

A tight feedback loop with measured impacts of an Epic with the use of big data enables experimenting with new service types. Some traditional companies have implemented collection of Big Data, but since they are missing Agile Portfolio Management, the feedback may be totally disconnected from the new development initiatives.

We have also plans to implement additional metrics, and to use relative metrics instead of absolute numbers. We also strive to visualize various data collected from users, and thus simplify how the development teams can please their users. We also hope to get incentives aligned and to support the agile portfolio kanban way of working. 


\section{CONCLUSIONS}

This paper has described how Agile Portfolio Management has been taken into use in Finnish Broadcasting Company Yle. We can conclude based on the experience that Agile Portfolio Management leads to:

1. A "Lean" portfolio - more standard solutions, less "halfbaked" solutions with the help of joined backlog

- Simple but working solutions that meet the need

- Better utilization of the resources via discussions and architecture analyses

- Capacity matching - do not start more work than what you can complete

2. Alignment

- Backlog structure creates better alignment and supports faster decision-making

- Better visibility than ever to all on-going activities

- With the help of a tool this visibility is all the time up-to-date

3. Focus on the work, not on approvals

- Resource approvals and purchase orders simplified

- Reduced time on paperwork and more focus on pleasing the actual users

- Transparency; real-time visibility on backlogs and progress

4. Better control on spending

- Control spending from first cent, ideas have to be proved before acceptance

- Optimization of solutions and using existing code to create new solutions

5. Options thinking: systematically nurture successes

- Visibility enables more nimble steering

- Start easier; prove concept to get more funding

Most importantly, Agile Portfolio Management creates tight learning loop from items under development and launch to user feedback. This moves the focus in the right direction, from internal approvals and competing setting to internal coordination, co-operation and competing against the external offering.

\section{ACKNOWLEDGMENTS}

We would like to thank the Yle management, especially Janne Yli-Äyhö and Ismo Silvo for supporting the deployment of Agile Portfolio Management - without your strong support and encouragement this change would simply not have been possible. We would also like to thank our colleagues and clients who are too many to be mentioned here who have contributed to and encouraged this effort.

\section{REFERENCES}

[1] Agile Software Development And The Factors That Drive Success. A commissioned study condicted by Forrester Consulting for HP. September 2012.

[2] Abrahamsson, P., Conboy, K., Wang, X., 2009. Lots done, more to do: the current state of agile systems development research.
[3] Dybå, T., Dingsøyr, T., 2008. Empirical studies of agile software development: a systematic review. Inf. Softw. Technol. 50, 833-859.

[4] Finnish Broadcasting Company, http://yle.fi/yleisradio/about-yle/this-is-yle

[5] Finnish Broadcasting Company, http://yle.fi/yleisradio/about-yle/yle-strategy

[6] Moore, G. Escape Velocity: Free Your Company's Future from the Pull of the Past. Harper Business, 2011. ISBN-13: 978-0062040893.

[7] Hitt, M. A; Keats, B. W; Demarie S, M. Navigating the new competitive landscape: Building strategic flexibility and competitive advantage in the $21^{\text {st }}$ century. The academy of management executive, 1998, 12(4): 22-42.

[8] Zeng, M, Dragons at your door: How Chinese Cost Innovation Is Disrupting Global Competition. Harvard Business Review Press, 2007. ISBN-13: 978-1422102084.

[9] Zhou, K. Z, Innovation, imitation, and new product performance: The case of China. Industrial Marketing Management, 2006, 35.3: 394-402.

[10] Reinertsen D, 2009. The Principles of Product Development Flow. Second Generation Lean Product Development. Celeritas Publishing, ISBN-10: 1935401009.

[11] Abrahamsson, P, Speeding up embedded software development. ITEA Innovation report, 2007.

[12] Christopher, M, The Agile Supply Chain. Industrial Marketing Management, 2000, 29: 37-44.

[13] Stalk, G. Time - the next source of competitive advantage. Harward Business Review July/August 1988.

[14] Version One, $8^{\text {th }}$ Annual State of the Agile Survey, http://stateofagile.com/

[15] Rico, David F., and CSM PMP. "What is the ROI of Agile vs. Traditional Methods?." TickIT International 10.4 (2008): 9-18.

[16] Laanti M, 2013. Agile Methods in Large-Scale Software Development Organizations. Applicability and model for adoption. Dissertation. University of Oulu. ISBN 978-95262-0033-0

[17] Laanti, M, Characteristics and Principles of Scaled Agile, Springer International Publishing, Agile Methods. LargeScale Development, Refactoring, Testing, and Estimation, XP 2014 International Workshops, Rome, Italy, May 26-30, 2014, Revised Selected Papers

[18] Arnold J, Yuce O, Black Swan Farming, using cost of delay: Discover, Nurture and speed up delivery of value, Agile 2013 conference

[19] Leffingwell D, 2011. Agile Software Requirements. Lean Requirements Practices for Teams, Programs, and the Enterprise. Addison-Wesley, ISBN-10: 0-321-63584-1, ISBN-13: 978-0-321-63584-6.

[20] Tengshe, A.; Noble, S., "Establishing the Agile PMO: Managing variability across Projects and Portfolios," Agile Conference (AGILE), 2007 , vol., no., pp.188,193, 13-17 Aug. 2007 doi: 10.1109/AGILE.2007.24

[21] Thomas J, C, Baker S, W, Establishing an Agile Portfolio to Align IT Investments with Business Needs, Agile, 2008. 
AGILE '08. Conference, vol., no., pp.252,258, 4-8 Aug. 2008 doi: 10.1109/Agile.2008.29

[22] Rautiainen, K.; von Schantz, J.; Vähäniitty, J., "Supporting Scaling Agile with Portfolio Management: Case Paf.com," System Sciences (HICSS), 2011 44th Hawaii International Conference on , vol., no., pp.1,10, 4-7 Jan. 2011, doi: 10.1109/HICSS.2011.390

[23] Stettina CJ, Hörz J, Agile Portfolio Management: An empirical perspective of practice in use. International Journal of Project Management, April 2014.
[24] Sirkiä, R, Laanti M, Adaptive Finance \& Control: Combining Lean, Agile and Beyond Budgeting for Financial and Organizational Flexibility, Proceedings of 48th Annual Hawaii International Conference on System Sciences, January 2015.

[25] Avison D, Lau F, Myers M \& Nielsen PA (1999) Action Research. Communications of the ACM 42(1): 94- 